
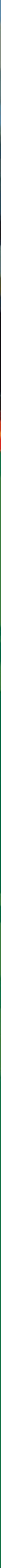


\section{2 \\ Government, non-government and community organisations in disasters}

\section{David King}

In the event of a disaster, communities become the targets of specialist organizations and undergo a concentration of activities. The complex unstructured activities and routines of daily life are disrupted and even totally overwhelmed by a single catastrophic event that requires a redirection of priorities, resources and people, to deal with all aspects of the disaster impact as rapidly as possible. The whole community must be mobilised to restore functions and meet needs, to return to the normality of the predisaster state. This latter purpose is least likely to be achieved, as the destroyed community can seldom rebuild to the same complex, but randomly haphazard state that existed before the disaster.

To mobilise the whole community to a single purpose of recovery, requires a high level of organisation. Response to a disaster demands that there be purposeful organisations ready to provide leadership and action. Emergency Management is predicated on the existence of such purposeful organisations. However, while organisations are at the core of Emergency Management Response and Recovery they are by no means simple or singular. Disaster generates the activities of a plethora of organisations, which interact with the community, rather than simply organising disaster response. The community also organises itself, re-assigning priorities and using existing organisations and networks.

\section{The Emergency Management Organisational Environment}

This chapter examines the range and roles of organisations that are involved in all aspects of disaster. The organisations are the structure of disaster Preparedness, Prevention, Response and Recovery, but the community and its citizens are the core of the effects of the disaster itself. In recognition of this Emergency Management has shifted its roles from a concentration on the traditional phases of Preparedness, Prevention, Response and Recovery to a much more community centred approach (Cronstedt, 2002). However, professional emergency managers, who have the greatest knowledge of such 
shifts in approaches and the reasons behind them, are only employed in some of the organisations that are involved in disasters. While the professional emergency managers may provide the most direct leadership and integrative structure to the tasks of dealing with disaster (Britton, 2001), the numerous other organisations that become involved have formerly existed to provide other kinds of services and functions which must be subsumed to deal with the immediate needs of a disaster. Thus although professional emergency managers in mainstream hazard oriented organisations may be aware of the complexity of the management and leadership roles that they are practising, this does not necessarily transfer to the managers and leaders of other organisations.

The traditional Emergency Management structure of Preparedness, Prevention, Response and Recovery (or its variant acronyms) is presented in Figure 2.1 below. These four processes structure the tasks of planning for likely disaster scenarios and for responding, and then reconstructing society and community in the event of a disaster occurring.

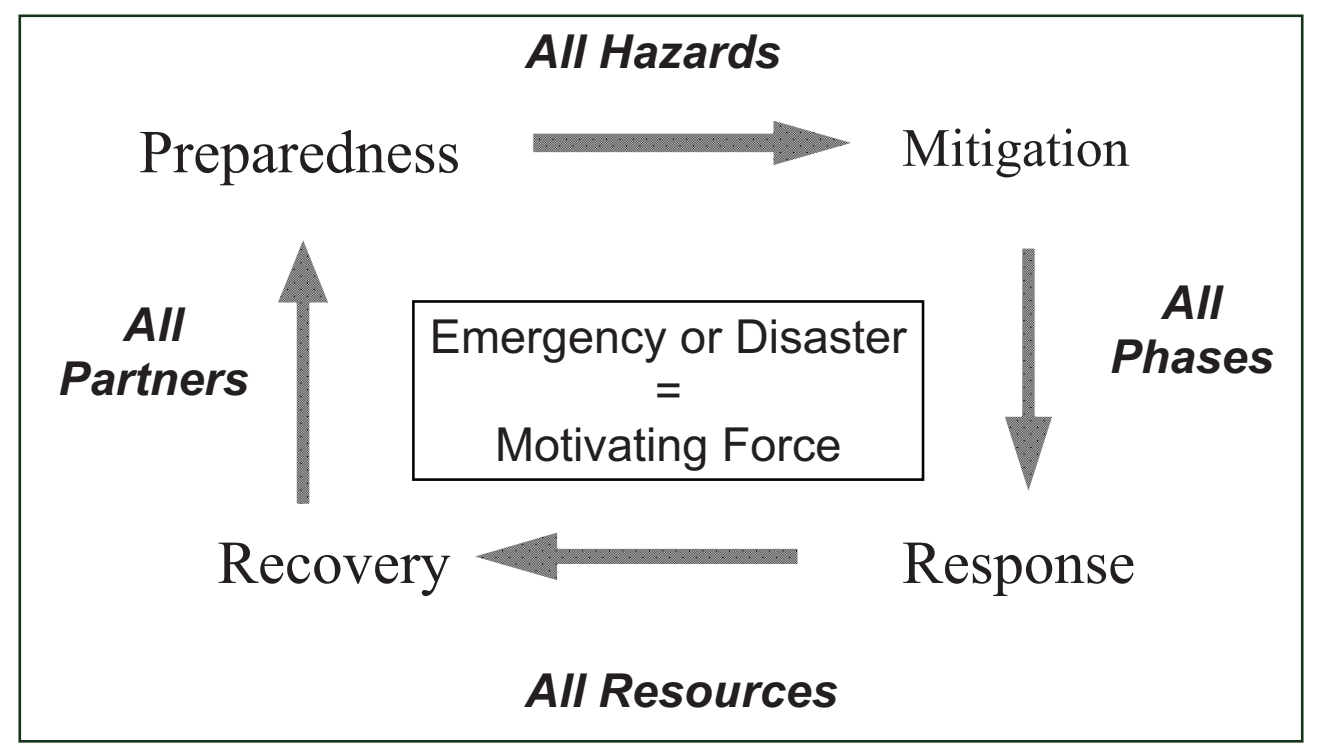

Figure 2.1 Integrated Emergency Management System (source: EMD, 2000)

Increasingly Emergency Management is using the term Mitigation as a larger group of activities that subsume both Preparedness and Prevention. The US Federal Emergency Management Agency (FEMA) uses preparedness and mitigation as separate stages. Emergency Management Australia (EMA) defines mitigation as "measures taken in advance of a disaster aimed at decreasing or eliminating its impact on society and the environment. See also prevention." (EMA, 1998, p. 76). 
Preparedness is defined as "arrangements to ensure that, should an emergency occur, all those resources and services which are needed to cope with the effects can be efficiently mobilised and deployed. Measures to ensure that, should an emergency occur, communications, resources and services are capable of coping with the effects" (EMA, 1998, p. 88). As a disaster is an event that is "beyond the day to day capacity of the prescribed statutory authorities and which requires special mobilising and organising of resources other than those normally available to these authorities" (EMA, 1998, pp. 32-33) the implication is that preparation is entirely contingent upon the scale of the disaster, which is presumably affected by preventive measures that have been put in place. The activities cannot exist separately. Preparing for a disaster will most likely initiate the process, but from then onwards both sets of activities are inextricably linked, reinforcing and complementary. As Emergency Management stakeholders have been using mitigation as an inclusive concept that subsumes preparedness and prevention, it has been used in that sense in Figure 2.1 above, partly in order to simplify a diagram that attempts to express the complexity of the stages of Emergency Management. However, it is irresponsible for any agency to prepare for a disaster without instigating preventive measures, even if these are as basic as information and warnings. The Emergency Management structure partially defines organisational roles and responsibilities, but has tended to portray them as steps or as a linear process, as in Figure 2.1. Many commentators (Cronstedt, 2002; Britton, 2001; Yates, 1999; Comfort et al., 2001) have criticised this linear model of Preparedness, Prevention, Response and Recovery.

These weaknesses and criticisms of the traditional model have led the author to develop a three-dimensional model as presented in Figure 2.2 below.

If the Emergency Management system is simplified into three main groups of activities: Mitigation; Response; and Recovery, there are distinct identifiable roles and responsibilities. Organisations fit into these three broad areas, but not as exclusive processes. Many organisations, both government and non-government, are involved in multiple aspects of disaster mitigation, response and recovery. All these elements are ongoing and interlinked and Figure 2.2 illustrates how these processes may operate simultaneously, interlinking and reinforcing. Mitigation is practised by all organisations and communities to varying degrees, even subconsciously or by seasonal routine. Mitigation of disaster impact is not a process that stops when hazard impact turns into a disaster. The disaster impact is part of the mitigation process in testing, challenging and confronting both the organisations and citizens. A process of learning and direct experience feeds back into mitigation, which grows in potential from the actual experience of the disaster. 


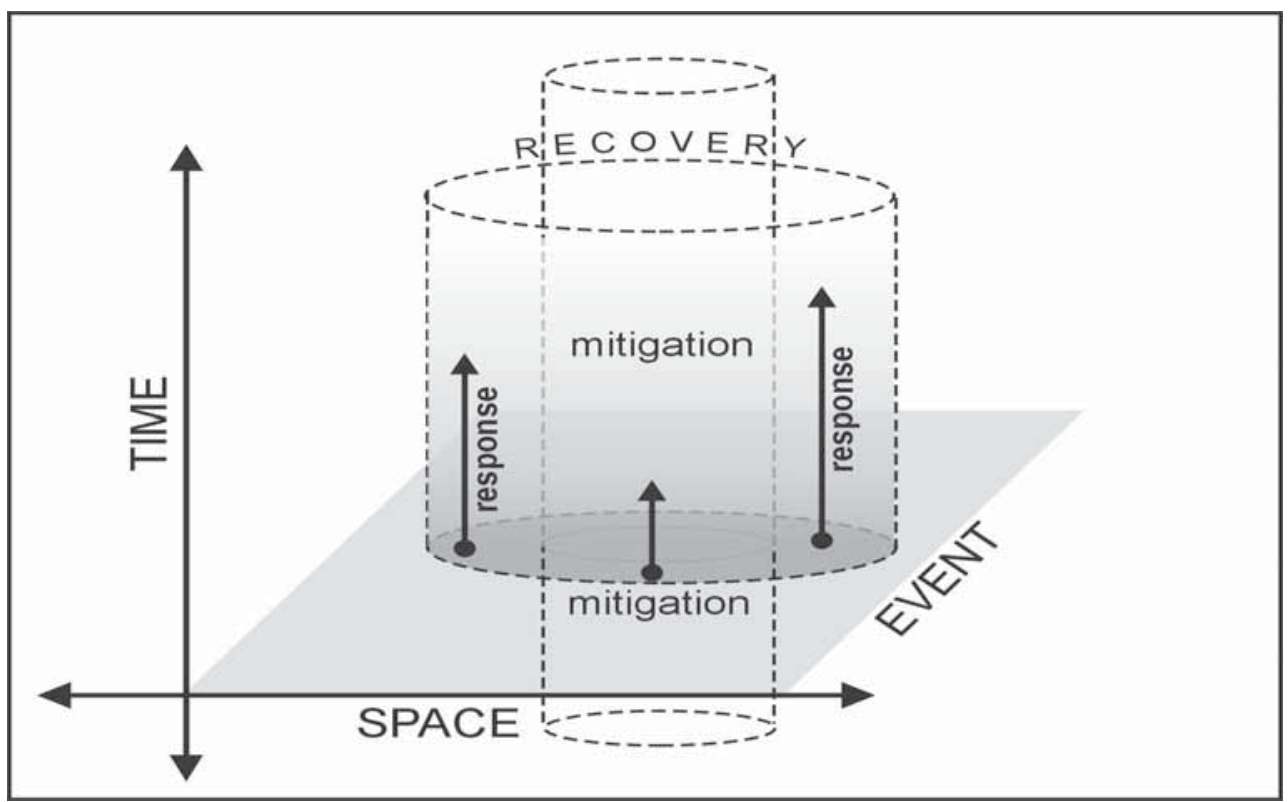

Figure 2.2 Mitigation, Response and Recovery in space and time

Thus mitigation is shown as an iterative and encompassing process. It proceeds through feedback loops, identifying and responding to shortcomings and needs. It can also appear to revert, or go backwards, as obstacles are confronted and mitigation measures fail or are too costly or difficult to implement. Mitigation can be made even more difficult through the contradictory efforts of different agencies. For example, road safety oriented street designs are concerned with traffic calming and a hierarchy of types of streets that reduce and slow local traffic. In flood or storm surge evacuation these design elements can create bottlenecks and congestion and may actually endanger lives. Levees provide short term protection, but in the long term may result in far more serious and widespread flooding. In other locations, flood drainage channels may also exacerbate flooding. The design of roads to act as drainage channels reduces their effectiveness in the event of evacuation.

Response has been typically the Emergency Management focus for a hazard impact or disaster. The reality of a disaster overwhelming the emergency services limits their initial response. The first response is from the impacted community. People who experience the direct effects of a disaster are not passive victims. They are active participants who will work through a range of organisations and networks to deal with the crisis. People may be traumatised, injured and suffering loss, but despite this they are the first 
people on the scene, the first to respond and the first to begin the recovery process. Recovery begins the moment a disaster happens (Sullivan, 2003).

The event also triggers a response in those organisations that have a responsibility or a role in the disaster. Preparation for a predictable and probable hazard is beyond being just mitigation, it is part of the response. Decisions have been made before the event that determine who will do what when the event happens. As citizens take shelter and carry out final precautions and preparations, the emergency organisations also position themselves to deal with the impact. Post-disaster studies in northern Australia (King, 2002) have shown that people leave a significant amount of preparation until the last minute, when the impact of the hazard is certain (or at least the probability is very high). All of the post disaster studies undertaken by the author in northern Australia have been floods and tropical cyclones, or both, which can be predicted to such an extent that people can feel confident in carrying out late preparations. The media refers to panic buying and last minute panic preparations, but observations of people and communities have not portrayed panic. In the immediate few hours before impact people are calm and purposeful in their behaviour, although most will express emotions that principally include concern, excitement and some degree of nervousness. In the tropical north of Australia people are advised to clear up potential debris at the beginning of the cyclone season, and to prepare an emergency kit. The fact that they delay this preparation until a cyclone or flood is inevitable, is a behavioural response that is mirrored by most organisations. Mental preparation and planning notes what needs to be done, but scarce resources cannot be allocated to the hazard response until it happens. Thus actions which are expected as preparations, are in reality postponed to become part of the response; a pre-disaster response. The response is therefore a direct outcome of mitigations and begins immediately before the hazard hits. The completely unexpected and extreme disaster has probably not been prepared for or mitigated against. Response and Recovery in such an event will begin immediately after it has happened.

Recovery is triggered by the response. It begins immediately after the disaster has occurred, but it is not a linear process (Sullivan, 2003; Cronstedt, 2002). The response to the disaster involves many different organisations, government and non government, each of which has separate roles, responsibilities and agendas. They carry out different tasks, at separate times and places, as well as overlapping and even sometimes competing with one another. In the ideal world all of these organisations would be coordinated by a single authority. In the developing world especially, this is frequently not the case.

A coordinating authority may exist, but it is frequently under-funded, poorly resourced, and even ignored by non-government organisations (NGOs), 
other government departments and politicians. This happened on a large scale in Papua New Guinea (PNG) following the Sissano Lagoon Tsunami disaster in 1998. To a lesser degree, coordination of the response to the impact of Cyclone Zoe on Tikopia and Anuta in the Solomon Islands in 2003 was constrained by a collapse of governance in that country, with the consequent inability of coordinating authorities to initiate a rapid response without outside assistance. Thus response is contingent upon the wealth of a nation, not just in terms of its physical capability, but more importantly in terms of governance.

The response phase can easily be poorly coordinated or chaotic. Even in the best of circumstances, the devastating impact of a disaster means that responses will come in pulses of activities that will inevitably occur separately in time and space. As response cannot be equal, recovery is most certainly not equal or linear. Recovery is also community initiated as well as developing from the organisational response. Community and organisational Response and Recovery efforts may proceed in parallel, virtually independent of one another. Again, this process of parallel recovery is far more likely to occur in developing countries, where a lack of pre-disaster infrastructure exacerbates problems of Response and Recovery.

Recovery proceeds in unequal pulses that involve a series of feedback loops as well as setbacks and secondary crises, such as public health emergencies that emanate from the initial disaster and redirect resources and efforts, thereby slowing the recovery process, and adding fresh impacts and trauma to the afflicted community. Recovery is an iterative process that develops opportunities as well encountering constraints.

\section{The Organisations}

It is within these complex interlinking phases of Emergency Management that organisations operate. Primary Emergency Management is generally practised by governments, with citizens reasonably expecting that emergency organisations will come to their aid in a disaster. Their expectations include a response from the army or defence force. The reality of a disaster is that the local emergency services and the civil functions of local government organisations are unable to cope, and the army does not necessarily have an Emergency Management role. Some countries use their defence forces to a greater extent than Australia, with civil defence having a much stronger relationship to military defence. Until 2001 Australia's peak Emergency Management body, EMA, came under the Department of Defence, although it was not answerable to the military, nor they to EMA, although EMA is a civil defence organisation in the event of war. However, it remains a misconception of many citizens that the defence forces will automatically be 
involved in a major disaster. On many occasions they have been involved, especially in such massive disasters as Cyclone Tracy in 1974 and 1975, but they only participate on request from civil authorities. This also applies to overseas relief operations, where the decision to use the defence forces is made by central government.

Emergency Management is therefore primarily a civil government activity, coordinated from the local level through state or provincial governments, up to a central government response depending upon the severity of the disaster (Douglas, 1999; Norman \& Coles, 2003). In developing nations a lack of resources, as well as traditions of military involvement in government, may result in a stronger reliance on military intervention in disasters. There are many developing nations that have a small or even no defence force, especially in the Pacific where only PNG and Fiji have armies. Although PNG has experienced a long civil war on Bougainville, its colonial and development experience put strong emphasis on its police and civil authorities, such that it's defence force continues to take a secondary role in disaster response.

Emergency Management is structured through laws that apportion responsibility for preparedness and prevention, and for response and recovery. For example in Queensland the Disaster Management Act 2003 (Queensland Government, 2003) specifies arrangements that are primarily carried out at the level of the local government. Local governments vary enormously in size and area. The smallest local government areas in northern Australia have less than 1,000 people and many have land areas in excess of 50,000 square kilometres. Their organisational capacity to deal with disaster is very limited, although the remotest parts of the north cope with floods and cyclones that in more developed parts of Australia would constitute a natural hazard or become a disaster. A similar resilience supports communities in remote parts of developing nations in South-East Asia and the Pacific.

Although legislation puts responsibility on local levels of government to prepare for disaster, the capability to respond adequately is limited. Apart from local government, disaster preparation is a requirement for all other government departments that provide social and welfare services to the community. In a disaster these needs are increased and are more urgent. Emergency Management coordinates the responses of all these government organisations, but they are separate entities answerable to different political masters. Each government department has its own priorities, agendas and needs, even within an atmosphere of cooperation. While many of these organisations have clearly defined, exclusive roles, such as health and police, organisations responsible for specific community members, such as the aged, 
or specific ethnic groups, may end up side by side providing very similar services.

Government is only one of many types of organisations that become involved in disasters. The trend in government has been towards less government and more privatisation. Former government roles in welfare and service provision are now provided by private enterprise. There is a blurred line between companies that are providing services to the public, and the traditional NGOs that began life as charities. At the further end of the business end of this continuum of organisations are companies that are in business to make profits for their shareholders, but which possess plant, machinery and expertise or infrastructure to play a very significant role in community recovery. Some companies are devastated or go out of business in a disaster, but for many others it is an opportunity for expansion, and inevitably profit, although individuals working for these companies may be no less motivated by altruism than members of government and relief organisations. The need to operate profitably does not in any way lessen their commitment to any of the phases of Emergency Management. At the same time they may even be able to provide services more efficiently and at a lower cost. That is often the aim of privatisation.

At the other end of this continuum are charities and humanitarian NGOs whose members are driven principally by beliefs, altruism and often a strong political agenda. However, the humanitarian NGOs have been undergoing quite dramatic changes to their roles. These issues and their impact on Emergency Management, especially in developing countries will be returned to later in this chapter.

On one scale there exists this continuum between altruistic NGOs at one end and purely commercial business operations at the other end. Stretching this scale is a size and spatial continuum that ranges from the international and national government organisations down to community, household and residual leadership. These ideas are expressed in Figure 2.3 in terms of these continua. 


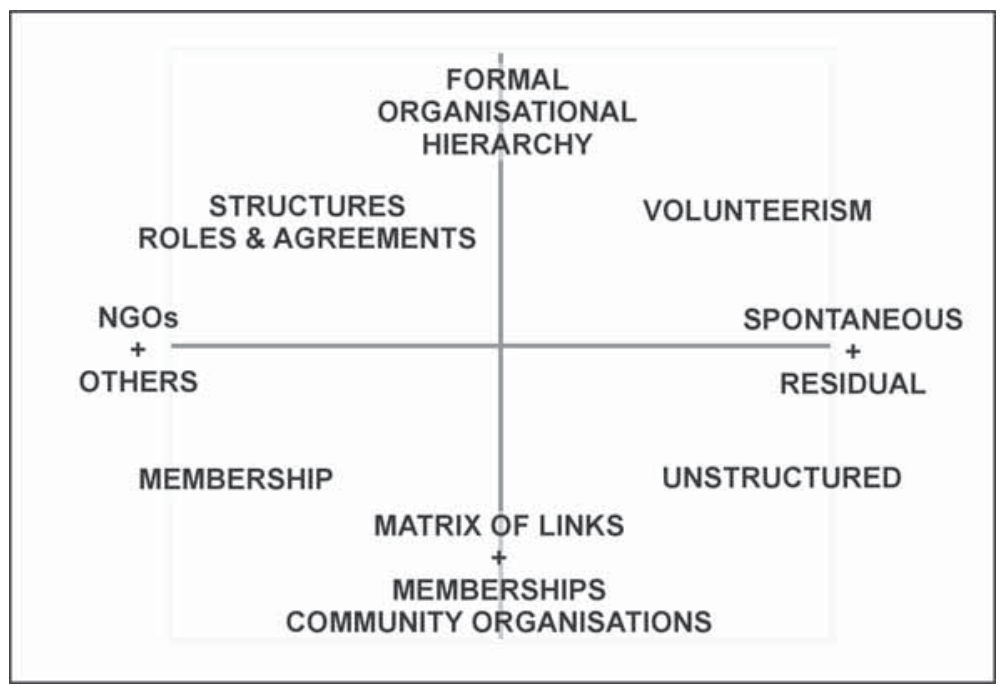

Figure 2.3 Organisation and membership of organisations

Table 2.1 below lists the types of organisations involved in Emergency Management and disaster response and recovery. The model expressed in both Figures 2.1 and 2.2 and listed in Table 2.1, is organisations coming together from diverse backgrounds to focus on a disaster event, within the dimensions of space, time and specialist roles and skills.

Table 2.1 Organisations involved in Emergency Management

\begin{tabular}{|l|l|l|}
\hline \multicolumn{1}{|c|}{ Direct } & \multicolumn{1}{c|}{ Indirect } & \multicolumn{1}{c|}{$\begin{array}{c}\text { Residual \& } \\
\text { Spontaneous }\end{array}$} \\
\hline $\begin{array}{l}\text { International } \\
\text { Organisations }\end{array}$ & Businesses & Culture \\
\hline $\begin{array}{l}\text { Non-government } \\
\text { Organisations }\end{array}$ & $\begin{array}{l}\text { Economic } \\
\text { Organisations }\end{array}$ & Community Networks \\
\hline Privatised Specialists & $\begin{array}{l}\text { Recreational } \\
\text { Organisations }\end{array}$ & $\begin{array}{l}\text { Internet } \\
\text { Organious }\end{array}$ \\
\hline $\begin{array}{l}\text { Grass Roots } \\
\text { Organisations }\end{array}$ & Cultural Groups & Residual Leadership \\
\hline $\begin{array}{l}\text { Community } \\
\text { Organisations }\end{array}$ & Interest Groups & Fixers \& Tradespersons \\
\hline & Political Groups & Illegal Groups \\
\hline & Media & Family \& Household \\
\hline & & Individuals \& Visitors \\
\hline
\end{tabular}


The organisations directly involved are those that have a primary responsibility for Emergency Management and disaster mitigation. Government organisations include all levels of government as outlined earlier. The NGOs include the traditional relief organisations and charities, but there are also NGOs that would be included in the indirectly involved group of organisations, such as Landcare, the formal organisations of religions, various types of youth groups that provide volunteers and so on. These are separate from organisations like the State Emergency Services (SES), which rely on volunteers, but are sponsored directly by government. However, many groups, including rural fire brigades, surf lifesaving clubs and others, are essentially community organisations. Grass Roots Organisations (GROs) are very definitely local community groups. Within the developing world, many GROs were formed as progress associations for the sake of advancing development, but adapted to relief and recovery in the event of a disaster. In the developed world GROs have often been single issue, but otherwise quite loose organisations. Some of these have responded directly to disasters or the threat of a hazard, as victim support or lobby groups, but there are far more GROs that are indirectly involved in disaster Response and Recovery (Fahey, 2003). They may not have been formed with any thought of hazard or disaster, but once formed they create and maintain community links and networks which may be rapidly used in a crisis.

The indirect group of organisations are those which exist primarily for a purpose other than hazard mitigation, but which contribute resources, personnel, networks and knowledge during and after a disaster. Included here are the media, in all of its forms and roles. The media are primarily a private enterprise industry, but it is crucial to government organisations and emergency managers who depend upon media response to get information, warnings and messages to the community. The media are often the earliest responders to a disaster, providing initial information and immediate impressions. When category five Cyclone Zoe hit the island of Tikopia, a remote and extremely isolated outlier of the Solomon Islands the first outsider to provide any news of the islanders' survival was a freelance journalist who chartered a helicopter from New Zealand. It is interesting that the journalist's initial report of devastation and survival described people fishing. Thus although the media comprised the first outsider, the Tikopians had got on with their own process of survival and recovery.

The media are also extremely powerful in advertising a crisis and prompting political and citizen response. The corollary of this power is the invisibility of unreported, or poorly reported disasters. Disasters are, in part, constructed by the media. They often exaggerate human interest elements, they look for scandals and government ineptitude, assign blame and instigate generous 
relief responses. They self censor some images of suffering, but are also guilty of misusing distressing images to increase the impact of their stories.

Emergency managers have no control over the media and need their positive support at all phases of Emergency Management. All organisations must therefore devote some of their resources to media liaison and must continually work at these networks. NGOs especially, work hard at developing their media image and ensuring media visibility as citizen generosity is a key component of their income.

There also exists a level of informal organisation that can be grouped under residual and spontaneous organisations. These are two quite separate community processes. The spontaneous response and resulting organisation, or community, or network, occurs directly as a consequence of the disaster event. The 'residual organisations' are those elements of civil society that underpin all that people do, the ways in which society is defined and constructed, the traditional, and the informal. Residual organisations are culturally constructed, grounded in community and civil society, representative of the ways people organise and network. This is not necessarily something ancient and 'culturally known', although it certainly includes that part of society, but it also includes all that is immediate and functional.

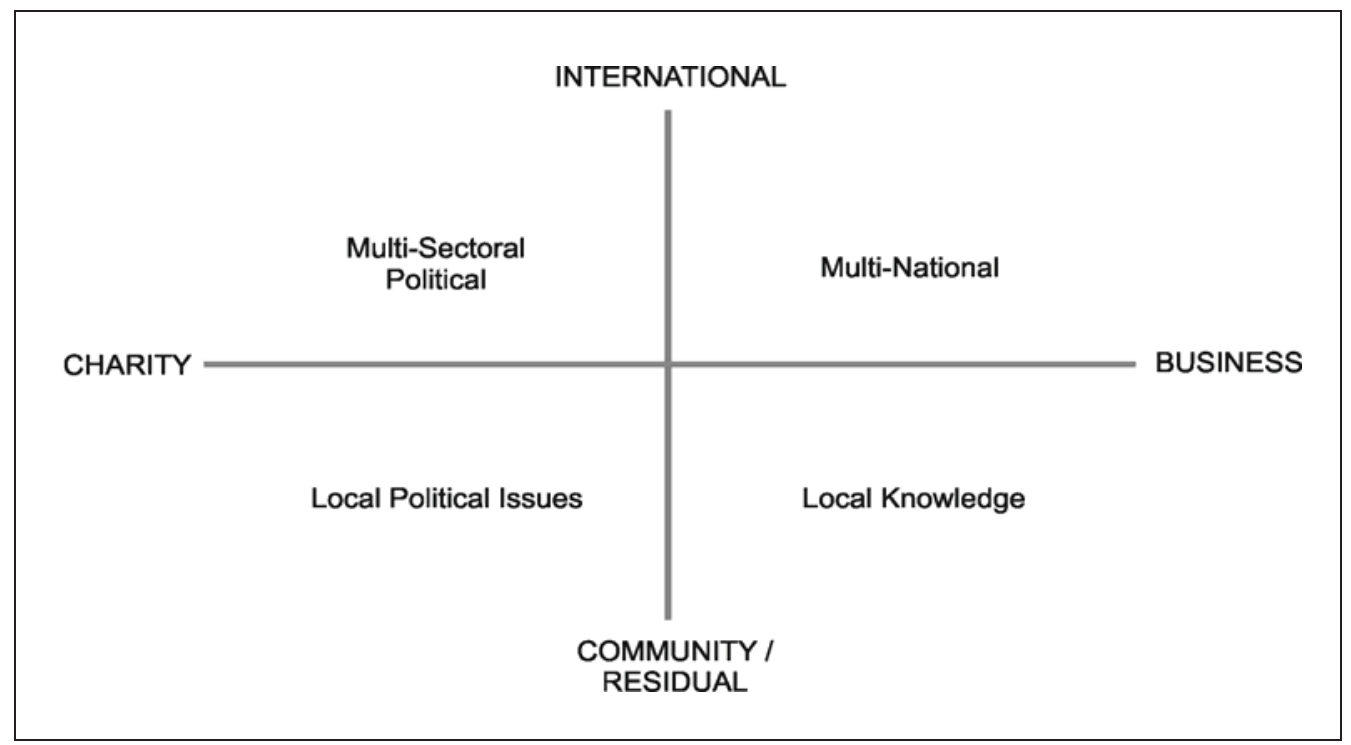

Figure 2.4 A matrix of types of organisations

The size and numbers of organisations that participate in any disaster vary with the spatial extent, the severity and the population that is involved. 
Obviously, the more organisations that are involved, the more complex is the task of Emergency Management. These organisations bring to the community a wide range of skills and approaches. These variations are illustrated in Figures 2.3 and 2.4.

Figure 2.3 expresses a range in size, organisational structure and scale. No organisation can encompass all of these types, they will sit primarily in one or more sectors. Figure 2.4 illustrates the variety of structures within organisations and the community. The upper left area is structured, the lower right is unstructured. Urban society, in particular, is a highly complex, unstructured matrix of networks and linkages. It is like the structure of the Internet, allowing enormous numbers of groupings and largely informal organisations (Alexander, 1966). This is the community which is managed by formal Emergency Management with its clear cut organisational hierarchy. Cutting across this continuum is a range of organisations from the formally structured NGOs which may include businesses and companies, through to the spontaneous and residual. Where the community initiates and pursues its own Response and Recovery, it is in the lower right area of the model, unstructured but not necessarily disorganised.

Thus it is inevitable in any disaster that problems of organisation and leadership will emerge. The effectiveness with which these issues are resolved will have a powerful influence on the effectiveness of Response and Recovery. Organisations will pursue their own agendas generating both contradiction and complementarity. Communities will pursue their own, often parallel, routes to Response, Recovery and Mitigation (Spillan, 2003; Palmer, 2001; Benini, 1999; Juratowitch et al., 2003; Silberbauer, 2003; Prater \& Wu, 2002; Loosemore \& Hughes, 2001).

\section{NGO Roles in Complex Emergencies}

The roles of NGOs in complex emergencies have been distorted away from needy communities towards the demands of governments and international agencies. Understanding the shift in the roles of NGOs raises issues that may help countries that have experienced a complex disaster, to better coordinate the naturally occurring processes of community recovery and redevelopment within a NGO policy. However, the problems and issues faced by the NGOs themselves are also complex.

Most NGOs involved in development have evolved from a humanitarian liberal and idealistic agenda, but performance in development has been ineffective or patchy, both sectorally and geographically (Edwards \& Hulme, 2002). With local knowledge and local institutional organisation, development NGOs found themselves well placed to intervene in relief when 
states collapsed and conflict emerged (Keen, 1998; Harvey, 1998; Edwards \& Hulme, 2001). Being reliant on donors for funding many NGOs found themselves beneficiaries of increased publicity as wars and associated natural disasters developed. It was easy to shift from development to relief when the budget expanded, although obviously to professionals committed to improvement in the quality of life in developing societies, there was no choice but to become involved in relief.

The accountability of NGOs is both to the donor and to the recipient, upward and downward. The end of the Cold War took many governments, such as the USA and USSR, out of direct aid competition in the developing world. Aid was both relatively reduced and channelled through international agencies and NGOs (Fowler, 2001; Reno, 1997). NGOs became more connected with donors who were bigger and more powerful (Edwards \& Hulme, 2001). Even though developing nation governments may have lost the ability to govern their own countries they have still been able to exert an influence on NGOs. This is acceptable and even necessary where coordination is needed, but it has added another level of accountability upward, to the detriment of downward accountability (Edwards \& Fowler, 2001; Keen, 1998; Edwards \& Hulme a \& b, 2001; Hilhorst, 2002). Thus NGOs are in greater danger of disengaging from direct partnership with disaster affected communities, while they serve instead the needs and agendas of host governments, private donors, donor agencies and Western donor governments.

The concept of political aid and a hierarchy of victims (Fox, 2001) challenge the political naivety of NGO relief efforts that indirectly (or directly through corruption and theft) support combatants and extend or exacerbate the conflict (Fox, 2001; Duffield, 2001; Macrae \& Leader, 2001; Keen, 1998). Thus on one side NGOs have been criticised for supporting corrupt governments by providing outside funded welfare projects, while on another side they undermine those same governments by enabling combatants to stay in business (Woodward, 2001), on yet another side they play into the globalisation agenda by practising privatisation of social services and international aid (Cliffe, 2000; Fowler, 2001; Edwards \& Hulme, 2001) and on the fourth side they have neglected accountability to, and partnership with, the community they exist to serve.

Against this background, the development NGOs have been drawn into increasingly complex conflicts, involving many players, unclear goals, struggles for resources and in some cases associated natural disasters; and all of the outcomes of displacement, medical crises; collapse of government and destruction of infrastructure. These 'new wars' of the new millennium or the twenty-first century, challenge all relief agencies to participate in the 
peace process as actively as the military organisations that are involved. Most of the 'new wars' have taken place in Africa, and they are symptomatic of a collapse of governance and development. Within the Asia Pacific region the East Timor conflict was the last of the 'old wars', a post-colonial struggle for independence, where there were clear goals on both sides. The collapse of governance in the Solomon Islands during 2002 and 2003 was more typical of the new conflicts and the complex humanitarian response. PNG faces the danger of similar disruption, while in Indonesia and the Philippines complex ethnic/political conflicts share many similarities with those of Africa. Of particular significance is the connection between economic setbacks and a slowing of development with the emergence of regional, ethnic and religious conflicts.

Firstly, the 'new wars' involve a dislocation of globalisation and network connections, especially in relation to the trade in cheap arms and the migrations of refugees (Cliffe, 2000). Secondly, these wars create their own political economies. The commonly used term 'warlord economies' (Reno, 1997), describes conflicts as a competition for resources that had formerly been controlled by the patronage system that had developed out of colonialism. Thirdly, the public and private spheres are blurred as combatants change sides, and mercenaries and criminals become involved. Fourthly, there are no significant political goals in these new wars. The 'new wars' are cheap wars (Keen, 1998; Richards, 1996) where terrorism or dominance of the unarmed civilian population is easily achieved, but the capacity to defeat a government is insufficient. The under-funded hand to mouth campaigns of such rebels contributes to their lack of goals.

As international agencies and NGOs move into a humanitarian disaster, alongside or parallel to community activity, the involvement of central government may facilitate or direct redevelopment within a broader political framework and development strategy. A strong civil society that works with NGOs may improve the developmental aspects of relief (Harvey, 1998). Civil society as a concept includes all the positive aspects of community, independent of the state and thereby the grassroots that presents a bottom up approach to development. Civil society is not totally undermined by disaster, but in the face of war or disaster it transforms and re-emerges. It is a rehabilitation model that is downwardly accountable and separate from state and donor politics. Its mechanism for reconstruction is to utilise community or traditional institutions and structures.

\section{Conclusion}

Organisations exist to respond to disasters and to reconstruct places and communities, but the circumstances of each disaster throw up unique problems and sets of complex issues that will stress and constrain even the 
most experienced disaster organisations. Disasters overwhelm. Most governments and government agencies, especially at the local area level that experiences the disaster impact, will have had little previous direct experience of dealing with an actual disaster. Organisations exist primarily to meet other needs and provide regular and routine services. In developed industrialised countries, governments and non-government organisations are overwhelmed by disaster, but when governance is much weaker, especially in the poorer countries of the world, formal organisations are even less likely to be able to respond or even to function at all. Added to weak governance, are issues of cultural pluralism, social and economic divisions, control of the state territory, and thus even the willingness, let alone capacity, of governments to provide aid or assistance to specific groups or locations.

Conventional models of Emergency Management presuppose that government and non-government organisations will proceed through regular processes to respond, aid recovery, and mitigate against future hazards. The reality is that capacity is far more constrained than Emergency Management processes portend. Also underplayed in formal organisational models is the role of virtually everyone else in responding to and recovering from a disaster. Community, business, non-formal organisations and individuals take actions to respond to hazards and recover from disaster without necessarily relating to the roles of formal organisations. Organising the organisational and non-organisational response is part of the process and chaos of any disaster. It is possible to identify all the levels and types of organisations and communities that have been examined in this chapter, but what each would do in the unique disaster event remains as unpredictable as the disaster impact itself. What is essential is the recognition by Emergency Management that it will always deal with the consequences of a disaster in partnership with a plethora of government, business and community organisations each of which has its own priorities, structures and procedures. 